\title{
WCCC 2015: the 21st World Computer Chess Championship
}

Article

Published Version

Krabbenbos, J., van den Herik, J. and Haworth, G. (2015) WCCC 2015: the 21st World Computer Chess Championship. ICGA Journal, 38 (2). pp. 102-113. ISSN 1389-6911 Available at https://centaur.reading.ac.uk/39948/

It is advisable to refer to the publisher's version if you intend to cite from the work. See Guidance on citing.

Publisher: The International Computer Games Association

All outputs in CentAUR are protected by Intellectual Property Rights law, including copyright law. Copyright and IPR is retained by the creators or other copyright holders. Terms and conditions for use of this material are defined in the End User Agreement.

\section{www.reading.ac.uk/centaur}

\section{CentAUR}

Central Archive at the University of Reading

Reading's research outputs online 


\title{
NEWS, INFORMATION, TOURNAMENTS, AND REPORTS
}

\section{WCCC 2015: THE 21 ${ }^{\mathrm{ST}}$ WORLD COMPUTER CHESS CHAMPIONSHIP}

\author{
Jan Krabbenbos, Jaap van den Herik, and Guy Haworth ${ }^{1}$
}

Amersfoort, Leiden and Reading

The $21^{\text {st }}$ edition of the World Computer Chess Championship was organized by the ICGA, LIACS and LCDS, and was held in Leiden University's department of computer science. The sponsors were Aegon, Museum Boerhaave, the municipality of Leiden, Leiden University, ICGA, ISSC, SURFsara, Digital Game Technology and NWO. It was held in conjunction with the 18th Computer Olympiad and the 14th Advances in Computer Games conference. Moreover, special lectures for the general public on intelligent programs for rowing, football and the game of Diplomacy were given. Additional sponsors were therefore the Faculty of Science, the Royal Dutch Rowing Federation and Dutch Angle.TV.

Over the period June $29^{\text {th }}$ to July $3^{\text {rd }}$, the authors, operators and nine programs engaged with each other in a round-robin. They are listed in alphabetical order in Table 1. Chess programmers' Wiki's and biographies are available on the web (CPW, 2015a-y). The exploitation of hyper-threading (Vlasák, 2015) varied across the hardware platforms used. The platform for JONNY was, as in 2013, a subset of the BTRZX3 cluster from Megware at the University of Bayreuth, specifically 100 nodes each having 2 AMD Opteron 6348 12-core processors. They communicated on a QDR Infiniband network of $2.5 \mathrm{~GB} / \mathrm{s}$. JONNY analyzed $2 \mathrm{bn}$ positions/s and added an estimated 350 ELO to the chess performance of JONNY on a single-core engine.

\begin{tabular}{|c|c|c|c|c|c|c|c|c|}
\hline & Program & Author(s) & Country & Ope rator & Cores & Thre ads & Architecture & $\mathbf{G H z}$ \\
\hline 1 & FRIDOLIN & Christian Sommerfeld & $\mathrm{DE}$ & Christian Sommerfeld & 4 & 7 & Intel i7 & 2.8 \\
\hline 2 & GINKGO & Frank Schneider & $\mathrm{DE}$ & Ingo Bauer & 6 & 6 & Intel i5 & 2.8 \\
\hline 3 & HIARCS & Mark Uniacke & GB & Harvey Williams on & 28 & 28 & Intel Xeon E5-2697 & 2.8 \\
\hline 4 & JONNY & Johannes Zwanzger & $\mathrm{DE}$ & Johannes Zwanzger & 2,400 & 2,376 & AMD x86-64 & 2.8 \\
\hline 5 & KOMODO & $\begin{array}{c}\text { Don Dailey, Larry } \\
\text { Kaufman \& Mark Lefler }\end{array}$ & USA & $\begin{array}{c}\text { Mark Lefler \& } \\
\text { Erdogen Günes }\end{array}$ & 24 & 24 & Intel i7 & 2.8 \\
\hline 6 & MAVERICK & Steve Maughan & USA & Steve Maughan & 1 & 1 & Intel i7 & 2.8 \\
\hline 7 & PROTECTOR & Raimund Heid & $\mathrm{DE}$ & Timo Haupt & 8 & 15 & Intel i7 5690x & 4.0 \\
\hline 8 & SHREDDER & Stefan Meyer-Kahlen & $\mathrm{DE}$ & Stefan Meyer-Kahlen & 16 & 16 & Intel i7 & 2.8 \\
\hline 9 & THE BARON & Richard Pijl & NED & Tessa Pijl & 16 & 16 & Intel E5-2687w & 3.1 \\
\hline
\end{tabular}

Table 1. The authors, operators and programs of the WCCC 2015.

The game tempo was 'all/105' + 15"/move'. The 36 games (symmetrically, 13 wins for White, 10 draws and 13 wins for Black) are available on the web as played (ICGA, 2015) and with evolving post-event comments (Krabbenbos et al., 2015).

\section{R1: GINKGO-HIARCS 1/2-1/2, JONNY-FridOLIN 1-0, KOMODO-MAVERICK 1-0, PROTECTOR-SHREDDER 1/2-1/2.}

The game GINKGO-HIARCS attracted quite some interest. It started as a Semi-Slav game following the variation once developed by Botvinnik. After move 17. ... c5 White was out of book but HIARCS continued to follow its book up to 20. b3. Thereafter it was instructive to see how Black managed to obtain the initiative. Black started a kingside attack and brought his own king to safety by castling queenside. Its attack was quite strong so it allowed itself to sacrifice the exchange for continuation of the threats around the white king. When the pressure was increased White did not see any alternative to sacrificing its queen so we saw a late middle game with rook and bishop against queen. One might think this was an easy win for Black. However, on move 40 (Figure 1a), the diligent program HIARCS made a move whose consequences it did not see.

The quintessence of the refutation was that after 40.... e5?, White could sacrifice the exchange to arrive at an endgame of queen against two bishops in which Black did not have the opportunity to enter the white fortress. Black tried in vain for 43 moves until a draw was agreed. After the game, the operators determined that the move 40.... Bd5 would have led to a win.

\footnotetext{
${ }^{1}$ jan.krabbenbos@gmail.com, jaapvandenherik@gmail.com and guy.haworth@bnc.oxon.org
} 
The game JONNY-FRIDOLIN showed the benefits of a new approach in computer chess programming. Today's chess engines are so strong that it is questionable whether book knowledge is preferable to computational knowledge. Both programmers adhere to the principle of having short lines in the book and then relying on the ingenuity of the program. This game is an excellent example of this strategy. Black left its book after 4. ... Nf6 and White left its book after 7. ... Qb6. Chess players know that the line they followed is a very interesting one including a pawn sacrifice by White to create active play. This is what the audience saw. White took the initiative but Black found many clever answers to the tactical threats that White posed. Nevertheless the continual stream of threats was too much for Black which found itself in a disadvantageous position. In the end, Black was forced to give up the exchange and had to resign a few moves later. A nice win by White and important for the competition for first place.

KOMODO-MAVERICK was a game in which both sides tried to trick the other. That is always a dangerous strategy but it is attractive for the public weighing the chances for both sides. Black started a kingside attack with h7-h5h4 whereas White was trying to occupy the center squares. The battle around the center was supported by Black's attempt to make matters complicated on the queenside. However in doing so, Black played too many queen moves so that ultimately no real progress was made. Moreover the kingside attack came to an end and now we saw a kind of turbulence in which all pieces were involved. White came out as the deserved winner which suggests that its calculations were deeper and more to the point. The final line was very easy but we are sure that most human players would have followed other lines instead of the exchange of pieces to arrive at a won pawn endgame. All in all, it was a deserved win for KOMODO, an early announcement that it was to be a major candidate for the title.

The game PROTECTOR-SHREDDER started with a quiet Sicilian opening following the Scheveningen variation. After 15 moves White was out of book. The continuations by White were promising but not spectacular. On move 25 (Figure 1b) in a position which was evaluated as equal, White took three minutes to move.

Almost at the end of that time period it changed its main line to 25. Rxc6. White estimated the position as being 0.5 pawns up. Black believed it was equal. In a complex midgame both sides tried to prove their own evaluation correct. White saw its estimated plus value diminishing to zero. Owing to the difference in material it was not clear what the outcome would be. For the genuine spectator it was difficult to understand the strategy that should be followed. It was a game full of tactics. Finally the material balance was recognized by both sides and after a considerable exchange of pieces the game ended in a draw.

Standings after Round 1: 1= JONNY and Komodo 1; 3= GINKGO, HiarCS, Protector and SHREDDER 1/2; $7=$ FRIDOLIN, MAVERICK and THE BARON 0.
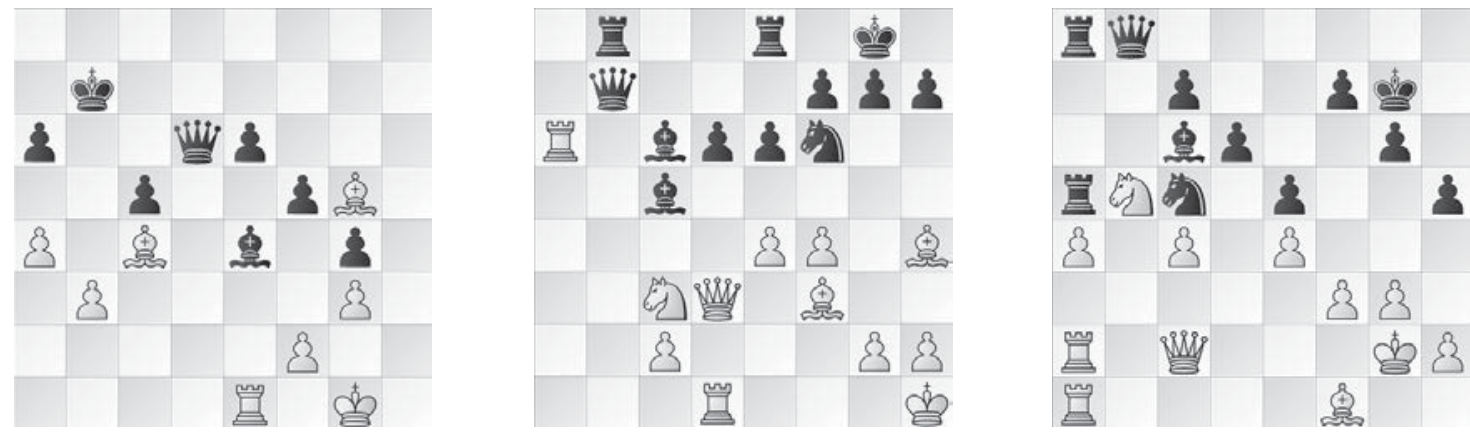

Figure 1. (a) R1 GINKGO-HIARCS after 40. Kg1, (b) R1 Protector-ShredDER after 24. ... Qb7 and (c) R2 FRIDOLIN-GinKGO after 30. Kg2.

\section{R2: SHREDDER-JONNY 1/2-1/2, MAVERICK-PROTECTOR 0-1, FRIDOLIN-GINKGO 0-1, THE BARON-KOMODO 0-1.}

The game SHREDDER-JONNY was a contest between two old rivals. In earlier editions of the WCCC, SHREDDER has been a well-established program and JONNY was the newcomer. After a second place in the $20^{\text {th }}$ world championship, JONNY is now a front rank program. The game played proved that both programs are of equal strength. In a Ruy Lopez variation introduced by Bird, the opponents tried to get a small advantage by modest means but both contenders operated securely. So the draw was agreed with sufficient material removed from the board. Johannes Zwanzger notes that, uniquely, he saw both sides scoring 0.00 throughout. 
The best review of the game MAVERICK-PROTECTOR is the remark that White lost the game. After an interesting Catalan opening, the midgame was a difficult strategic position and here, White's plan was too simple. White played Bd4-e5-d6-c5-d4 but by this manoeuvre allowed Black to have excellent places for its pieces. The outcome of the manoeuvre was 25. Bxf6, giving Black isolated, doubled f-pawns. However the compensation was a pawn majority of two pawns on the queenside which led to Black creating a passed pawn, converting on $\mathrm{d} 1$ and winning White's bishop. This decided the game although White played some additional moves before conceding the win.

In the game FRIDOLIN-GINKGO, both sides started to play the English opening quietly. With small means each contestant tried to obtain some advantage. It resulted in a passed a-pawn for White and excellent squares for the black pieces. This was the dominant theme in the whole game. At one moment (Figure 1c) we saw the a-file occupied by four rooks with a queen protecting the a-pawn diagonally.

Obviously the a-pawn could not be taken, so with so many forces protecting it, Black changed its strategy to the kingside and started to penetrate with queen and knight. It was not successful in terms of mate or material gain but positional advantage was sufficient. Black waited for the opportunity to start a final attack. White defended cleverly but could not prohibit the tactical manoeuvres that resolved the position for black. Up to the very end the a-pawn was White's last hope but when it disappeared the game was over, a well deserved win for Black.

THE BARON-KOMODO was an exciting game. In many tournaments THE BARON has shown its power by its results against top programs. KOMODO playing the Caro-Kann was facing the advance of the e-pawn to e5. This always leads to interesting games. Indeed, Black sacrificed a pawn by 13. ... d4 for positional pressure, see Figure 2a.

THE BARON reacted very actively and the best KOMODO could do was to recapture the pawn. In the resulting midgame position the chances were equal. Both sides were eagerly looking for weak points in the opponent's fortifications. For the spectators it looked like both sides were able to reach their aim on the queenside. That was remarkable and deeper analysis would give us a definitive verdict. As things went in the game, THE BARON committed suicide by sacrificing a pawn for unclear chances in a king attack. Black defended adequately and assuredly demonstrated good technique with a pawn up. All in all, an exciting fight.

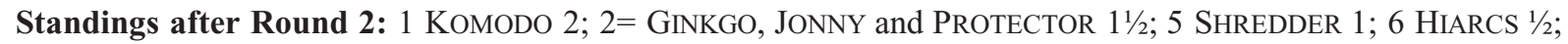
$7=$ FRIDOLIN, MAVERICK and THE BARON 0.
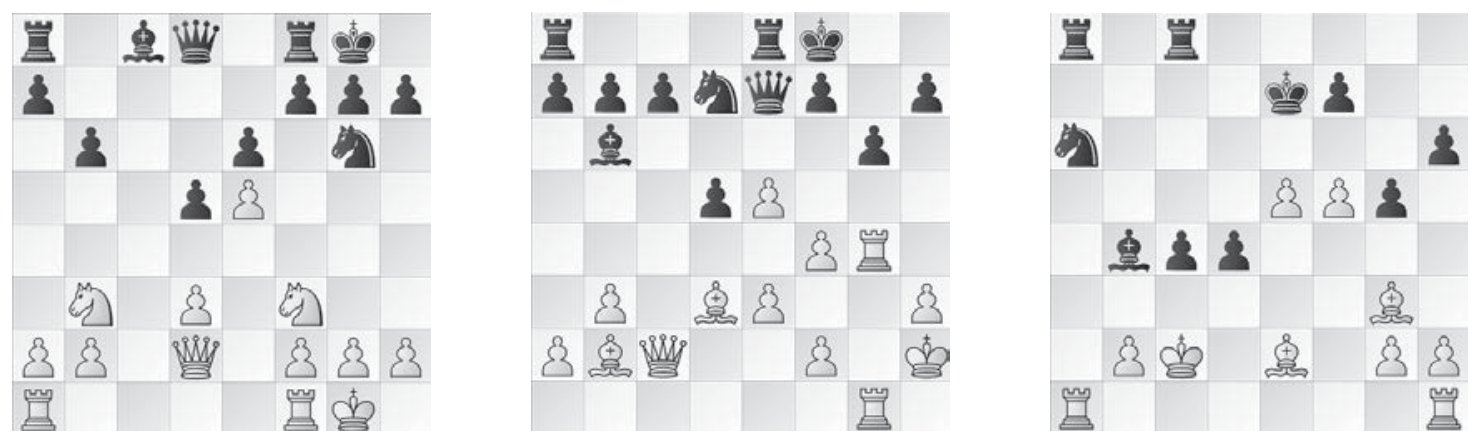

Figure 2. (a) R2 THE BARON-KOMODO after 13. cxd3,

(b) R3 HiARCS-Fridolin after 20.... Kf8, and (c) R3 PROTECTOR-THE BARON after $23 . .$. d4.

\section{R3: JONNY-MAVERICK 1-0, HiARCS-FridOLIN 1-0, PROTECTOR-THE BARON 1-0, GinKGO-SHREDDER 1/2-1/2.}

The game JONNY-MAVERICK started as a closed Sicilian Defense. In this type of position, most games evolve rather quietly but this game was an exception. Right at the beginning Black tried to take the initiative, first on the queenside and then in the center. JONNY was not impressed and reacted adequately. It took over the initiative and soon we saw Black searching for good moves. The most important advantage White achieved was that it prohibited Black from castling. After the black rook on h8 had moved, castling was not an option and from the grandmaster perspective the game was lost. JONNY showed it was able to perform at this level and soon decided the game in its favour. 
In chess, strategy and tactics fight for priority. Currently, finding strategies by deep calculations seems to be most important in computer chess. The strongest programmers assume that their brainchilds are strong enough to find their own way. Mark Uniacke is such a strong programmer. In the game against FRIDOLIN, HIARCS played 1. b3. Operator Harvey Williamson reported after four moves: "We are out of book." Black played actively in the center and temporarily offered a pawn. However the complications which came on the board took all its attention and there was no time to recapture the weak pawn in the center. And then all of a sudden the weak pawn turned out to be a strong pawn so HIARCS had a won position. The program then showed that it was also able to play very strongly in a tactical vein, see Figure $2 b$.

By 21. Bxg6, it showed that sacrificing some pieces to gain Black's queen was a long-term variation which had been evaluated as a win for White. Replaying the game is a simple task. Producing the right moves at the right time is an ability which only strong chess programs nowadays have. A deserved win for HIARCS.

In the game PROTECTOR-THE BARON, the Semi Slav opening occurred again. Botvinnik would have smiled had he seen this descendant of his thoughts appearing in the tournament. The game went as he had imagined: a very hard fight with chances on both sides. In his time Botvinnik remarked "The more complex the situation, the better it is for the stronger player." We are not sure whether this statement holds for the current chess programs. They may see deep variations and evaluate them with a range of criteria. For human beings it is nowadays difficult to estimate who is better. In the game it looked like Black was better and White had to do its utmost to sustain counterplay. However hidden resources and ripostes turned out to play an important role. In the position of Figure $2 \mathrm{a}$ it is not even clear whether the two black pawns in the center are stronger than the two white pawns on e5 and f5. The latter two do not appear to be really threatening but their strength is their presence. The game was very turbulent after $\mathbf{2 4}$. Bf3.

Both programs estimated the general exchange that took place as resulting in an equal game. Yet in the position on the board there were new unexpected possibilities. The pair of bishops gave White the upper hand even though Black was an exchange up. White played the endgame very well and deservedly won.

GINKGO-SHREDDER was an addition to the collection of rare games in the world of computer chess. It started as Queen Indian game following the Nimzowitsch variation. White tried to have the advantage from its first move but could not find any tangible objectives to aim at. When Black started with its first threats, White closed the position and Black had no opportunities to open the configuration. There was one place were Black could employ its pieces and try to have an open fight, namely on the kingside. However before Black could be dangerous White was able to close the position there too. Now we had a remarkable configuration with only a few possibilities to enter the opponent's fortress. On move 43 Black played a6, so the e and f pawns comprised a major wall on the board. The g-file with pawns on $\mathrm{g} 3$ and $\mathrm{g} 6$ was the only opportunity to try some initiative. The casual observer will not see that both sides did in fact make real attempt to make something out of the opportunities given: 50 moves were played without a pawn move. Experienced chess players know what this means but established chess programs know that it is time for a joke. So with great style, Black played 93. ... Qg4, sacrificing a queen and simultaneously claiming a draw.

Standings after Round 3: $1=$ JONNY and PROTECTOR 21/2; 3= GINKGO and KOMODO 2; 5= HiARCS and SHREDDER 1 1 $\frac{1}{2} ; 7=$ FRIDOLIN, MAVERICK and THE BARON 0.

\section{R4: Komodo-Protector 1-0, SHredder-Hiarcs 0-1, THE BARON-JonNy 0-1, MAVERICK-GinkGO 0-1.}

In the game KomOdO-PROTECTOR, playing chess looks easy. KomOdo relied on the Nimzovich-Larsen opening 1. Nf3 d5 2. b3 Nf6. Both sides placed their pieces on the relevant squares and in time exchanged pawns and pieces. Still, White seemed to play with more knowledge and intuition than Black, for instance doubling the rooks on the c-file, creating an isolated, black d-pawn and exchanging a knight for a bishop to advantage. The outcome of these small advantages in combination was the capture of a pawn. The resulting endgame was difficult but playing with a pawn up gives opportunities and challenges the opponent. Step by step, White managed to improve its advantage and won the game in a straightforward way.

From one game it is difficult to assess whether it is played either by human grandmasters or by computers of grandmaster level. The game SHREDDER-HIARCS provided an excellent example of this. HIARCS played the Sicilian opening, in particular the Najdorf variation. Black chose a strategic line in which it sacrificed a pawn for active play on the black squares. This initiative developed well in the position with pressure on the white pieces and pawn structure. Continuous pressure led to White deciding to return the pawn in the hope of finding relief. 
Black took the pawn and expressed the wish to keep the initiative even though it had to sacrifice the exchange by 37. ... Rxc4, see Figure 3a.

With bishop and pawn versus rook, Black was master of the board. However the question was whether it was sufficient for a win. From a comfortable position Black managed to develop play on the kingside with an attack, on the queenside by mobilizing the pawn majority and in the center by using the squares as a hub for supporting both sides. White did its utmost but had to return the exchange and allow Black to arrive at a queen ending with a passed pawn. The game was in a technical phase and HIARCS was unstoppable, bringing in the full point. This game is a very good example of the playing strength of current computer programs.
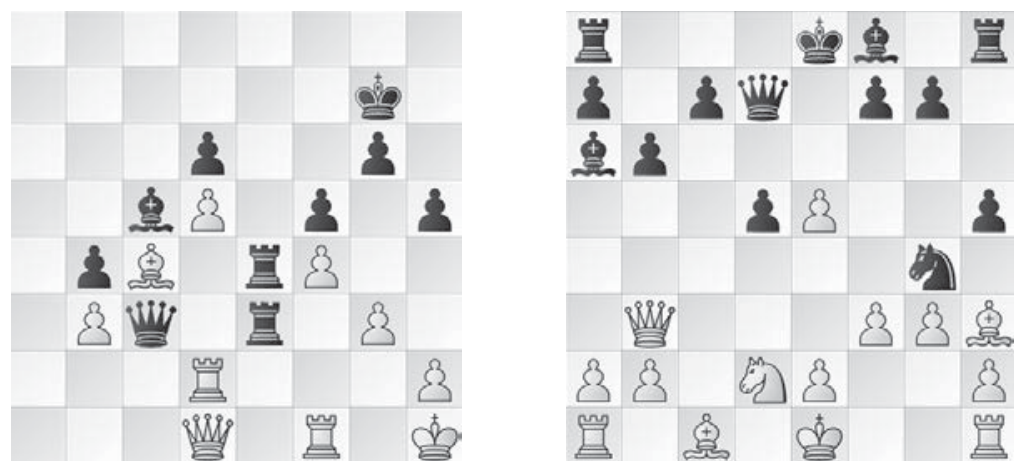

Figure 3. R4 (a) SHREDDER-HIARCS after 37. Bc4 and (b) THE BARON-JONNY after 12. f3.

The game between THE BARON and JONNY was a demonstration of power from JONNY. After a Queen's Indian opening JONNY played some challenging moves. THE BARON accepted the challenge and managed to win a full piece against a pawn, see Figure $3 \mathrm{~b}$.

However JONNY was scoring 1.62 up, Black's position was overwhelming and another pawn was won. The white pieces were placed in a cramped situation on ranks 1 and 2. Black developed all its pieces smoothly and gained another two pawns on the queenside. With four pawns for the piece the material balance was now in favor of Black. Pieces and pawns penetrated the white position and soon the white king resigned.

The opening in the game MAVERICK-GINKGO was a Semi-Slav. Both players seemed to know what they had to do. Black reacted quiet actively but White's ripostes were adequate. White sacrificed a pawn for a better pawn structure but postponed recapture of the pawn and believed that active play was better. However Black made use of the time given to it by small tactics. At one moment, it was clear that the small tactics had given Black the best chances and that thereafter White would have to fight for a draw. This was in fact unattainable and Black's win was fully deserved.

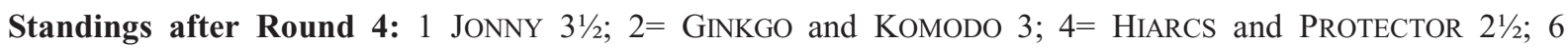
SHREDDER 11ㄹ; $7=$ THE BARON, MAVERICK and FRIDOLIN 0.

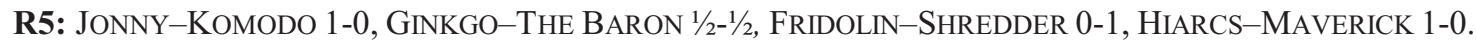

In the fifth round the favourite program for the title KOMODO played the quietly fancied JoNNY. After a Slav opening both programs showed equal strength. In fact we could argue that the game started after 37 . ... Bxh8 (Figure 4a). The moves played from this position were very subtle and neither side induced the other to make a mistake up to the position after 129. Nf2 (Figure 4b). At this juncture Black decided to be active and played the double-edged move 129. ... Nxa4. It was the beginning of a disaster which was very difficult to see coming. While scoring 3.84, JONNY played 140. Ka4 and after 144... Be6 the quintessence of the winning line appeared on the board: 145. Na8! (Figure 4c).

Perhaps KOMODO did not see this as the start of a losing line when the motif was repeated but JONNY'S score was now up to 5.36. After move 149. Kb6, the plan was clearer to both programs and onlookers who were by now three deep and in awe of what was being revealed. Once the idea was clear, the moves played themselves but each advance by the white king must have given great satisfaction to Johannes who later declared this "a studylike win: a masterpiece". JONNY delivered a top performance here to secure the win but both programs were applauded for creating a remarkable game. 

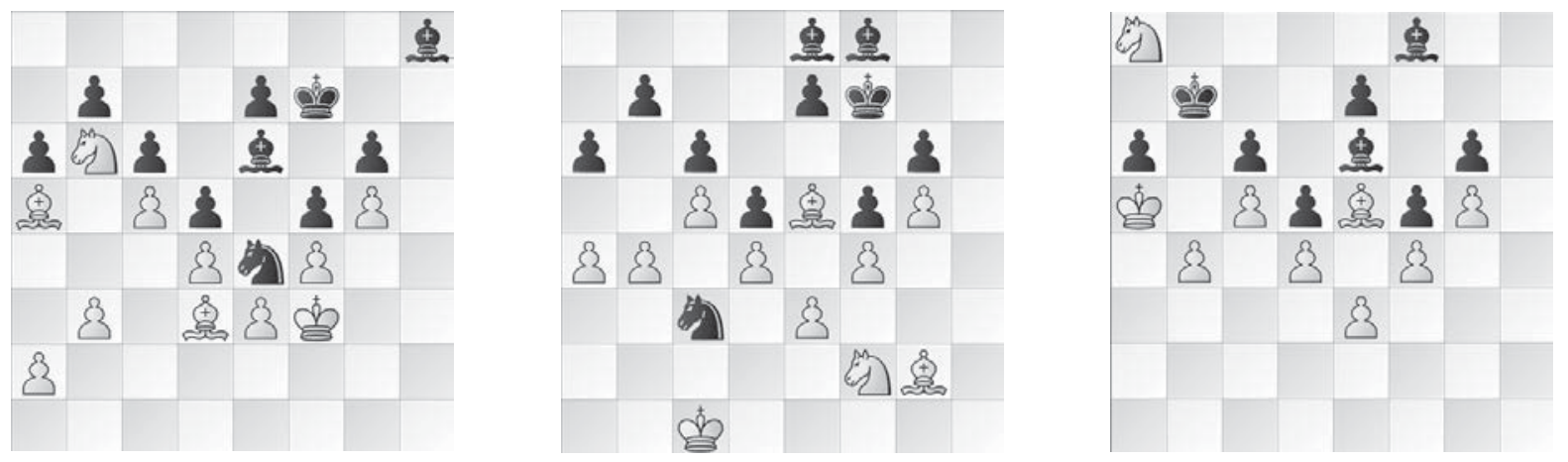

Figure 4. R5 JONNY-KOMODO after (a) 37... Bxh8, (b) 129. Nf2 and (c) 145. Na8.

The game GINKGO-THE BARON was equal and both players seemed to be satisfied with a draw. However programs nowadays have their own intentions and THE BARON showed this by trying to win a pawn but it was at the cost of a displaced rook. White had the initiative, regained the pawn and had some advantage. Black understood what it should do, namely to aim for a drawn position. With some clever manoeuvres it arrived at a KRNKR endgame tablebase position. A draw was agreed by the operators.

Although FRIDOLIN managed to play the opening on an equal footing, it was no real match for SHREDDER. Stefan Meyer-Kahlen's program took the initiative by a simple king attack. The black pawns marched to the white king and were not stopped by any counterplay. It resulted in a pawn capturing a rook on e1. At that moment, the game was over although the play continued for a few more moves. With this win, SHREDDER managed to remain in the middle of the pack.

In HIARCS-MAVERICK we saw a quiet game at first but soon HIARCS challenged MAVERICK to be active. MAVERICK replied with overactive play which might impress the layman but not an experienced program like HIARCS. Both programs had seen that the surprising move 27. ... Qxg4+ (Figure 5a) led to a lost position for Black. The continuation of the game was predicted by the principal variations of both engines. All in all, a deserved win for HIARCS.

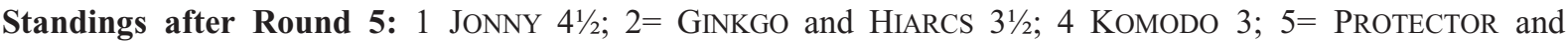
SHREDDER $2 \frac{1}{2} ; 7$ THE BARON $1 \frac{1}{2} ; 8=$ FRIDOLIN and MAVERICK 0.

\section{R6: PROTECTOR-JONNY 1/2-1/2, THE BARON-HIARCS 1/2-1/2, KOMODO-GINKGO 1-0, MAVERICK-FrIDOLIN 1-0.}

The game PROTECTOR-JONNY was a Catalan opening in which, soon after the opening, the contest focused on taking the initiative. As is usually the case, initiatives are higher ranked than material advantage. So we saw a clash of styles, both programs trying to find the answer. It is difficult for the objective commentator to put more weight on the material balance even though an imbalance exists on the board. It is always difficult to give preference to a minor piece with some passed pawns over a rook which is active but cannot find any weak points in the opponent's fortress. After a long series of moves both programs decided to share the point.

THE BARON demonstrated that it is a solid program. Playing against HIARCS is quiet some task these days but THE BARON played a flawless opening, reaching a normal middle game and being able to exchange the most important pieces. HIARCS tried to bring some music to the position but THE BARON correctly danced at the right tempo, keeping a sufficient distance apart. All in all, HIARCS was unable to tempt THE BARON into a risky move and finally both programs agreed to a draw.

After the Bird opening, KOMODO tried to develop smoothly and hoped to win straight out of the opening. However GINKGO was alert and defended well. In difficult positions the best players always find the best alternatives. That happened in this game too. It looked like GINKGO had sufficient counterplay but KOMODO built a strong position with its pawns assisted by a rook. The dynamic position at the end turned out to be a win for White although Black could have provided more resistance.

After a start in an Old Indian variation a tough fight took place between MAVERICK and FRIDOLIN, two programs in the lower half of the tournament. Their play was understandable and it was not clear whether they were aiming at one specific goal or were playing acceptable moves, meanwhile seeing which position would be the next 
station in their journey. The exchange of pieces and pawns finally led to a run of Black's e-pawn versus advancing the white pawns on the queenside. Although Black was first, it resulted only in gaining the exchange. The white pawns finally decided the game.

Standings after Round 6: 1 JONNY 5; 2= HiARCS and KOMODO 4; 4 GINKGO 31²; 5 PROTECTOR 3; 6 SHREDDER $2 \frac{1}{2} ; 7=$ MAVERICK and THE BARON 1; 9 FRIDOLIN 0.
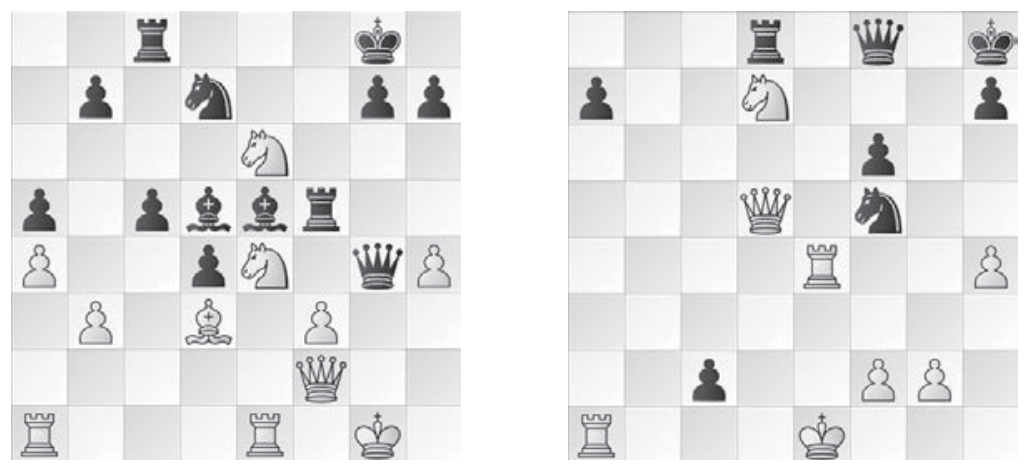

Figure 5. (a) R5 HIARCS-MAVERICK after 27. ... Qxg4+ and (b) R7 HIARCS-KOMODO after 26. Nxd7.

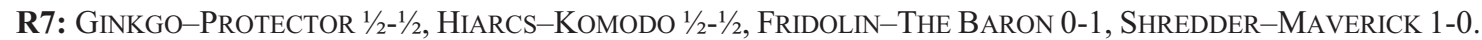

GINKGO-PRoteCtor was a Queen's Gambit, Slav variation: they followed the main line of a quiet variation. The game can be characterized by two features. First White had an isolated d-pawn and a knight whereas Black had a black-squared bishop and a weak c-pawn. As these characteristics dominated the position both tactically and strategically, both sides placed and adjusted their pieces repeatedly. No progress was seen and after 67 moves which were of interest to the programs but not to the onlookers, they agreed on a draw.

HIARCS-KOMODO was an exciting game from the beginning. They played a Slavic variation of high complexity. Black castled on the kingside but White decided to develop via h4 and Rh3. It looked like White had started an overwhelming kingside attack which prevented Black from strengthening his majority position on the queenside. However Black intelligently found a chance to weaken the attack by sacrificing the exchange. White took the scrimmage in the center as a basis to resolve the majority of black pawns on the queenside. Here Black showed a nice trick by saving one pawn in particular, even bringing it to the square $\mathrm{c} 2$. For the general spectator it looked like a pawn which had lost its way, see Figure $5 b$.

However Black showed that it had a deep plan in mind for this pawn: it played 26. ... Qa3. Clearly the c2 pawn is pivotal to the whole development after this move. The situation remained unclear since White picked up a knight after a series of exchanges but it transpired that it could not save that minor piece advantage. Remarkably, the complexities did not lead to a win for either side but resulted in a rook ending with three pawns against two. This was a draw although Black had to play precisely.

The game FRIDOLIN-THE BARON is a nice example how an experienced program such as THE BARON addresses the normal moves as played by FRIDOLIN. To play a game well, programs should be active and inventive. Good moves are most of the time not sufficient to achieve a good position as the programs are in competition for subtleties. With this perspective on the position, we see that THE BARON succeeded in steadily obtaining small advantages which finally resulted in a tangible advantage. Some technical decisions still had to be taken in the right order before a win could be recorded on the score sheet. In this game THE BARON did what the public expected: it won the game convincingly.

SHREDDER-MAVERICK was more exciting than could be expected, given their back histories. SHREDDER is a program which has seen all the ins and outs of the computer chess world: MAVERICK is a newcomer. In the Sicilian opening both sides played well. Still, SHREDDER managed to collect some small advantages which could be valuable in a later phase in the game. Some tangible items were a passed a-pawn, a nice square on d5 for the knight and a weak pawn on the b-file. These three features were combined harmoniously by SHREDDER and were in fact the basis for its win. The game provided MAVERICK with an opportunity to learn about how such positional elements can combine. The way to the top is long and winding but deserves to be pursued. 


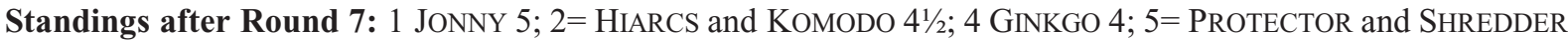
31/2; 7 THE BARON 2; 8 MAVERICK 1; 9 FRIDOLIN 0.

\section{R8: JONNY-GINKGO 1-0, KOMODO-Fridolin 1-0, THE BARON-SHREDDER 0-1, PROTECTOR-HIARCS 1/2-1².}

At the beginning of this round three programs had some hope of the title. For all three it was therefore important to win their game against one of the programs which were no longer candidates in the running. JONNY and KOMODO fulfilled their expectations. However HIARCS had to allow PROTECTOR a draw in a game in which it never had the chance of a better result. In fact the game PROTECTOR-HIARCS is a demonstration of the level of playing strength computer programs have reached today. Strategically it was an interesting game but there were no moments of excitement and a draw was the logical outcome.

Chess is a game of decisions. Playing a strong game is about taking the right decisions at the right moment. In many games it is possible to attain some advantage by positional play but then it is difficult to get more advantage. Therefore a well planned, well timed decision is necessary. JONNY played an interesting Stonewall opening against GINKGO. Both programs were well aware of the strategic requirements the position imposed and both took the right small decisions. JONNY was able to achieve some small positional advantage. The power of JONNY is its calculation engines. JONNY playing with 2400 cores is the master of distributing smaller tasks to these cores for computing particular configurations.

After 25. ... a5 (Figure 6a), JONNY decided to sacrifice the exchange to reach an endgame in which White was compensated for the exchange by one point only. JONNY was scoring 1.90, having calculated that this endgame was very favorable for White. Progress was slow but definitive even though it relied heavily on computation. A nice example of the deep thinking by JONNY is given in the Figure 6 b position after 49. ... Re7. Such moves are a jewel in the crown and the remainder was played at the same level. A very much deserved win for JONNY, giving strong support to its aspiration to become World Champion in the last round.

The similarity between a weaker program and a very strong program is that they both play unexpected moves. The difference between the two programs is that the unexpected move by the stronger player is a strong move with a clear meaning. The unexpected move by the weaker player is a surprising move, leaving the spectators guessing as to its meaning. With this guideline in mind it is a pleasure to replay the game between KOMODO and FRIDOLIN. For human players, many moves were surprising moves. The line of thought followed by KOMODO resulted in a win which in fact showed that it outclassed FRIDOLIN.

THE BARON versus SHREDDER was again a game between a sub-top and a top class program. THE BARON played the opening well but the transition from opening to middle game was played better by SHREDDER. It is remarkable how the best modern programs understand when to sacrifice a pawn for active play and when to gain a pawn. SHREDDER developed very active play and was clearly the first to attack its opponent's king. The attack by White on the black king did not start at all. Under pressure from the black pieces, White had to give up an exchange for a pawn but the pressure continued and soon its surrender was unavoidable. For SHREDDER it was a last chance to reach the top four.

The pairings of the last round left the end result in doubt and it was clear that the tournament would have an exciting finish.

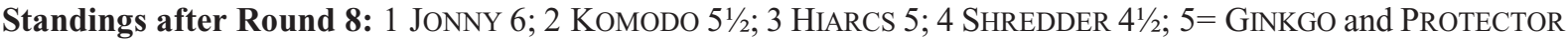
4; 7 THE BARON 2; 8 MAVERICK 1; 9 FRIDOLIN 0.

\section{R9: Hiarcs-JONNY 0-1, SHrEdDER-Komodo 0-1, Fridolin-Protector 0-1, MAVERICK-THE BARON 0-1.}

In the final round, two games were of importance as the top two programs were involved. JoNNY was Black against HIARCS and KOMODO was Black against SHREDDER. To become world champion the program should be a master of the details of chess complexity. JONNY distributes this complexity over 2400 cores and KOMODO relies on grandmaster knowledge which is meticulously implemented in the program. Below we will see no difference in the outcome since both programs won. But the thinking and the way in which these two results were achieved were quite different. 

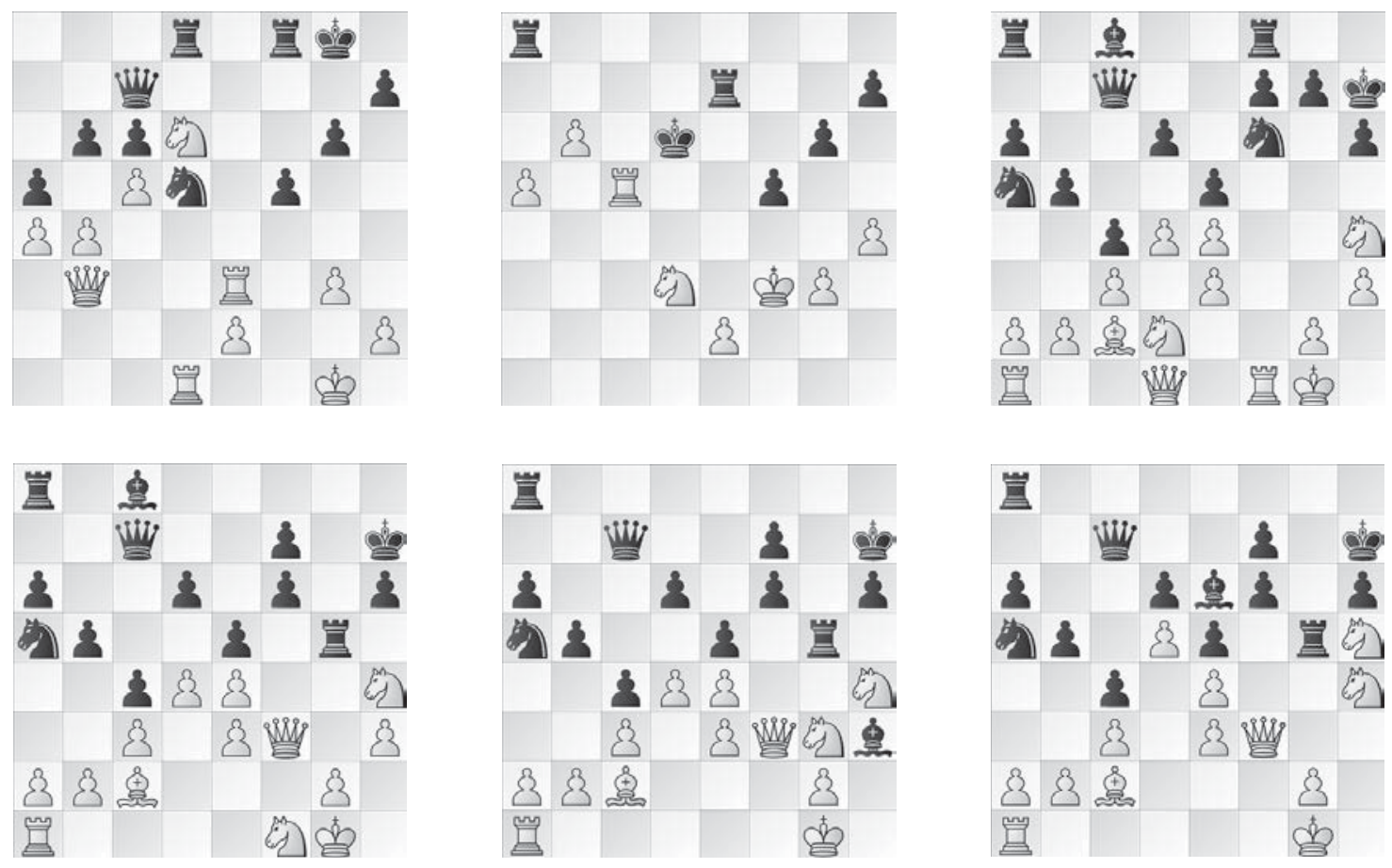

Figure 6. R8 JONNY-GINKGO after (a) 25. ... a5 and (b) 49. ... Re7;

R9 Hiarcs-Jonny after (c) 16.... Kh7, (d) 19.... Rg5, (e) 20. ... Bxh3 and (f) 22. d5.

HIARCS-JONNY started as an Italian game following the Giuoco Piano variation, which means in translation 'quiet, quiet, quiet'. Both programs had their own covert ambitions. On move 9, Black exchanged the black squared bishops giving White the half-open f-file. It was an important decision as that file could then be the basis for a king attack by White. Black believed it had a position from which it could defend all possible threats. However, after 16. ... Kh7 (Figure 6c), it must have been surprised by White sacrificing the exchange with 17. Rxf6.

After this, White had to decide how to continue with its positional attacking ideas. It did so with 18 . Qf3 and 19. Nf1. In the meantime, Black positioned its rook on g5. That position, Figure 6d, was very interesting. White started a deep search, to decide between the moves 20. g4 and 20. $\mathrm{Ng} 3$. Afterwards, we may say that this was the critical position of the game. It is believed that $\mathrm{g} 4$ is the better move and potentially would lead to a win. However $\mathrm{Ng} 3$ was also very attractive, as the game will show in particular because Black had some hidden ripostes which could not be computed at the time that White had to decide upon its move.

After 20. Ng3, Black played the rather surprising 20.... Bxh3, Figure 6e. It is impossible to say that this move is a refutation of $\mathrm{Ng} 3$ (21.gxh3? Rxg3 22. Qxg3 Rg8) but it led to very sharp play. The game continued with 21. Nh5 Be6 22. d5 and now Black had to evaluate a difficult situation because securing the bishop leads to a disadvantaged position where the kingside cannot be adequately protected.

Therefore Black decided to play 22. ... Rf8. In the complex situation, White recaptured a piece and tried to continue its attack. Black was alert and defended the materially unbalanced position as well as possible. From the human point of view though, it appeared to do so without any plan.

At move 44, Figure 7a, the queens were exchanged and an endgame of three minor pieces against rook and minor piece was reached. The general opinion was that the result would be a draw, giving KOMODO a chance to draw level on points. However JONNY was on its best form, excelling by partitioning its calculation tasks over the 2400 cores available. In the endgame JONNY found almost incredible manoeuvres and fully outplayed HIARCS. Almost every five moves deserve a diagram to understand the fine details of JONNNY's play. On move 92, HIARCS decided to resign. JONNY became the new World Champion: it won convincingly and fully deserves the $21 \mathrm{st}$ WCCC title. Congratulations! 

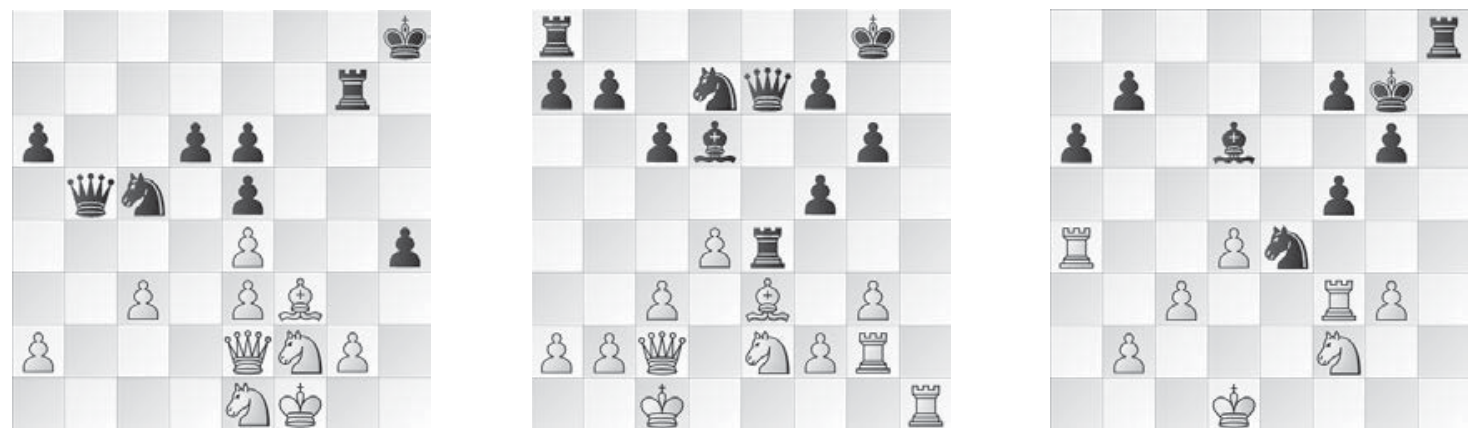

Figure 7. R9 (a) HIARCS-JONNY after 44. Qe2, and (b/c) SHREDDER-KOMODO after 18. Rg2 and 41. Ra4.

SHREDDER is a multiple world champion. It played in the last round against KOMODO, the brainchild of Don Dailey and a program strengthened by the efforts of grandmaster Larry Kaufman. He has scrupulously analyzed the details of strong pawn formations, promising pawn formation and interesting pawn formations. In fact he was doing data science before the term was coined, arriving at statistically correct conclusions from many examples. The game against SHREDDER is a fantastic demonstration of the power of the knowledge as implemented. The game started with a quiet Caro-Kann. At the moment that White threatened to double its rook on the h-file by playing 18. Rg2, Figure 7b, Black played its deep riposte.

In some sense, 18. ... Rxe3 is a forced move since it takes the power from the white attack. Moreover, after the queen exchange there is an interesting endgame in which White seems to be material up (a rook versus a piece and pawn). However, Kaufman had also included in the evaluation the promising power of the three pawns versus one difference on the kingside. The white compensation on the queenside, 4 against 3, had lesser weight. The continuation of the game is a brilliant proof of these simple thoughts. After 41. Ra4, Figure 7c, it is clear what Komodo had in mind when it sacrificed the exchange at move 18. From here, Komodo reached its preferred configuration and was able to win the game by technical means. A performance of high quality had been delivered, giving KOMODO the second place in this championship behind JONNY.

FRIDOLIN-PROTECTOR was a game that showed the difference in decisions. Both players were confident of their position after the opening phase. In the middle game, it is a matter of building up a structure which has consequences for the ultimate endgame. Such decisions require a large amount of experience in combination with the possibility to articulate the findings in a computer program. Apparently PROTECTOR had done its homework better than FRIDOLIN. It is true that FRIDOLIN is a rather strong program but the other programs are definitely stronger and that is what makes the difference. In the game it turned out that the white kingside was weakened and the d-pawn was not a strong passed pawn, but a weak pawn. Moreover the black pawns on the queenside were more threatening than the combinatorial force of the white pieces. Consequently black combined all this assets and won the game rather easily.

MAVERICK-THE BARON was a game between partners with a considerable difference in playing strength. MAVERICK started to play quietly but decided at the start of the middle game to become active. That was a difficult decision and the way it became active was definitely not the best one. White's position worsened with every move and finally Black reigned supreme over the whole board. White was eager to learn from Black and played on to a position where White was almost empty-handed.

JONNY is the new World Computer Chess Champion with KOMODO second (6.5/8) and with HIARCS and PROTECTOR sharing third place. Congratulations go to them and to all participants for a memorable tournament featuring the highest standards of play.

Standings after Round 9: 1 JONNY 7; 2 KOMOdO 61/2; 3= HIARCS and PROTECTOR 5; 5 SHREDDER 41/2; 6 GINKGO 4; 7 THE BARON 3; 8 MAVERICK 1; 9 FRIDOLIN 0. 

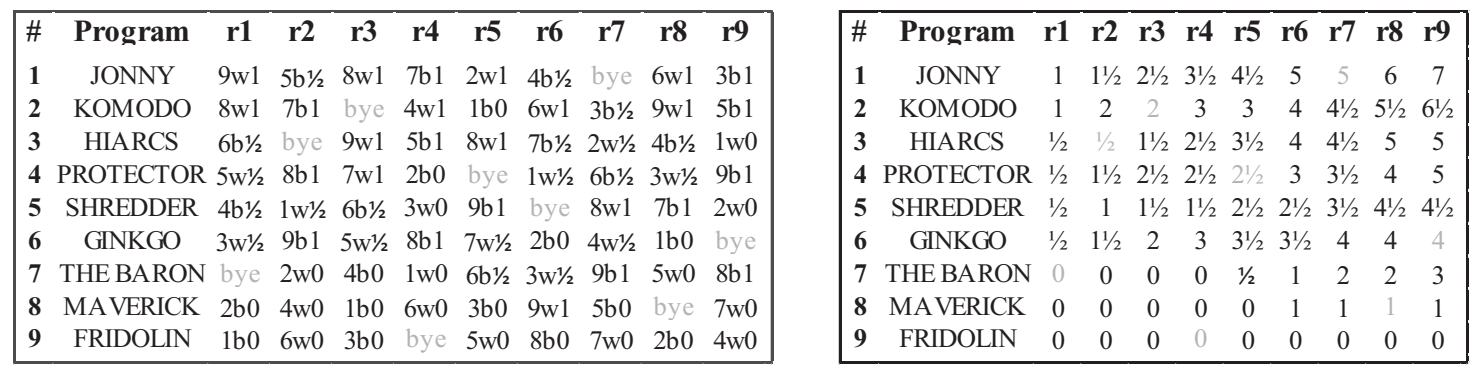

Tables 2 and 3. The WCCC 2015 game results and standings per round.

\begin{tabular}{|cccccccccccccccc|}
\hline \# & Program & J & K & H & P & S & G & B & M & F & W & D & L & Score S-Bgr \\
$\mathbf{1}$ & JONNY & & 1 & 1 & $1 / 2$ & $1 / 2$ & 1 & 1 & 1 & 1 & 6 & 2 & 0 & 7 & 24.25 \\
$\mathbf{2}$ & KOMODO & 0 & & $1 / 2$ & 1 & 1 & 1 & 1 & 1 & 1 & 6 & 1 & 1 & $61 / 2$ & 20.00 \\
$\mathbf{3}$ & HIARCS & 0 & $1 / 2$ & & $1 / 2$ & 1 & $1 / 2$ & $1 / 2$ & 1 & 1 & 3 & 4 & 1 & 5 & 14.75 \\
$\mathbf{4}$ & PROTECTOR & $1 / 2$ & 0 & $1 / 2$ & & $1 / 2$ & $1 / 2$ & 1 & 1 & 1 & 3 & 4 & 1 & 5 & 14.25 \\
$\mathbf{5}$ & SHREDDER & $1 / 2$ & 0 & 0 & $1 / 2$ & & $1 / 2$ & 1 & 1 & 1 & 3 & 3 & 2 & $41 / 2$ & 12.00 \\
$\mathbf{6}$ & GINKGO & 0 & 0 & $1 / 2$ & $1 / 2$ & $1 / 2$ & & $1 / 2$ & 1 & 1 & 2 & 4 & 2 & 4 & 9.75 \\
$\mathbf{7}$ & THE BARON & 0 & 0 & $1 / 2$ & 0 & 0 & $1 / 2$ & & 1 & 1 & 2 & 2 & 4 & 3 & 5.50 \\
$\mathbf{8}$ & MAVERICK & 0 & 0 & 0 & 0 & 0 & 0 & 0 & & 1 & 1 & 0 & 7 & 1 & 0.00 \\
$\mathbf{9}$ & FRIDOLIN & 0 & 0 & 0 & 0 & 0 & 0 & 0 & 0 & & 0 & 0 & 8 & 0 & 0.00 \\
\hline
\end{tabular}

Table 4. The WCCC 2015 cross-table of game results.

We finish with some sidelights and footnotes. There seems to be a trend towards less reliance on opening books. KOMODO's connections planned to play on a 200-core machine but in the event had to settle for a 24-core machine. The long and memorable game, JONNY-KOMODO, was crucial to the eventual outcome of this WCCC. Karsten Müller (2015) appropriately sees White as the Trojans, storming Black's Carthaginian fortress, sacrificing a horse to pave the way for its King and eventually winning all. Indeed, the game was a classic.

As to the endgame, some 16 or the 36 games entered the 'endgame table zone' (ETZ) where sub-7-man EGTs (de Man, 2013; Nalimov et al., 2000) can be used, where 7-man DTM EGTs (MVL, 2015) can be consulted later or where FINALGEN (Romero, 2012) could in principle (but not necessarily in practice) compute an endgame table. As Table 5 shows, no points were conceded in this zone and 3-minute, 2-core evaluations by DEEP FRITZ 14 indicate that the results were usually already clear.

\begin{tabular}{|c|c|c|c|c|c|c|c|c|c|c|c|c|c|c|c|c|c|c|c|}
\hline \multicolumn{3}{|c|}{ WCCC } & \multicolumn{5}{|c|}{ FinalGen } & \multicolumn{6}{|c|}{ 7-man } & \multicolumn{5}{|c|}{ sub-7-man } & \multirow{2}{*}{$\begin{array}{l}\text { Game } \\
\text { result }\end{array}$} \\
\hline$\#$ & & ame & move & $\# \mathbf{n}$ & nen & eval. & value & move & endgame & eval. & value & $d t m$ & ply & move & eval. & value & $d t m$ & ply & \\
\hline 01 & 1.3 & $\mathrm{~K}-\mathrm{M}$ & $48 w$ & 9 & $5-4$ & 16.60 & $?$ & $49 b$ & KQPPKRP & 15.4 & $1-0$ & $-34 p$ & 4 & $51 \mathrm{~b}$ & 11.53 & $1-0$ & $-42 p$ & 2 & $1-0$ \\
\hline 02 & 2.2 & $\mathrm{M}-\mathrm{P}$ & $43 w$ & 14 & $7-7$ & -6.25 & $?$ & & - & - & - & - & & - & - & - & - & - & $0-1$ \\
\hline 03 & 4.1 & $\mathrm{Sh}-\mathrm{H}$ & $52 \mathrm{~b}$ & 10 & $5-5$ & -1.07 & $?$ & $90 w$ & KQPKQPP & $-\infty$ & $0-1$ & $-24 p$ & 9 & - & - & & - & - & $0-1$ \\
\hline 04 & 4.3 & $\mathrm{M}-\mathrm{G}$ & $44 b$ & 12 & $6-6$ & -5.06 & $?$ & $49 w$ & KBPKRPP & -7.38 & $0-1$ & $-40 p$ & 13 & $55 \mathrm{~b}$ & $-\infty$ & $0-1$ & $25 p$ & 1 & $0-1$ \\
\hline 05 & 4.4 & $\mathrm{~K}-\mathrm{P}$ & $40 \mathrm{~b}$ & 13 & $7-6$ & 1.18 & $?$ & - & - & - & - & - & - & - & - & - & - & - & $1-0$ \\
\hline 06 & 5.1 & $\mathrm{G}-\mathrm{B}$ & & - & - & - & - & $60 \mathrm{~b}$ & KRNPKRB & 0.22 & $=$ & $=$ & 1 & $61 w$ & 0.36 & $=$ & $=$ & 1 & $=$ \\
\hline 07 & 5.2 & $\mathrm{~F}-\mathrm{Sh}$ & $47 \mathrm{~b}$ & 13 & $8-5$ & -4.19 & $?$ & - & - & - & - & - & - & - & - & - & - & - & $0-1$ \\
\hline 08 & 5.4 & $\mathrm{H}-\mathrm{M}$ & $52 w$ & 11 & $5-6$ & 19.56 & $?$ & $58 w$ & KQPKP(3) & $+\infty$ & $1-0$ & $17 p$ & 1 & - & - & - & - & - & $1-0$ \\
\hline 09 & 6.1 & $\mathrm{P}-\mathrm{J}$ & $65 w$ & 13 & $6-7$ & 0.00 & $?$ & & - & - & - & & - & - & - & - & - & - & $=$ \\
\hline 10 & 6.2 & B-H & $36 \mathrm{~b}$ & 14 & $7-7$ & 0.55 & $?$ & - & - & - & - & - & - & - & - & - & - & - & $=$ \\
\hline 11 & 6.4 & $\mathrm{M}-\mathrm{F}$ & $46 b$ & 12 & $7-5$ & 8.09 & $?$ & - & - & - & - & - & - & - & - & - & - & - & $1-0$ \\
\hline 12 & 7.1 & Sh-M & $47 w$ & 7 & $3-4$ & 4.96 & $1-0$ & $47 w$ & KNPKP(3) & 4.96 & $1-0$ & $55 p$ & 1 & $47 b$ & 11.93 & $1-0$ & $-54 p$ & 15 & $1-0$ \\
\hline 13 & 7.3 & $\mathrm{H}-\mathrm{K}$ & $35 b$ & 9 & $5-4$ & 0.73 & $?$ & $50 \mathrm{w}$ & KRPPKRP & 0.05 & $=$ & $=$ & 3 & $51 \mathrm{~b}$ & 0.37 & $=$ & $=$ & 0 & $=$ \\
\hline 14 & 7.4 & $\mathrm{~F}-\mathrm{B}$ & $43 b$ & 13 & $7-6$ & -2.52 & $?$ & & - & - & - & & & - & - & - & - & - & $0-1$ \\
\hline 15 & 9.2 & $\mathrm{H}-\mathrm{J}$ & $92 \mathrm{w}$ & 10 & $5-5$ & -5.70 & $?$ & & - & - & - & & - & - & - & - & - & - & $0-1$ \\
\hline 16 & 9.4 & M-B & $63 w$ & 6 & $3-3$ & -12.92 & $0-1$ & $61 b$ & KRBPKQP & -11.2 & $0-1$ & $41 p$ & 3 & $63 w$ & -12.9 & $0-1$ & $-40 p$ & 24 & $0-1$ \\
\hline
\end{tabular}

Table 5. WCCC visits to 'ETZ', the endgame table zone. 


\section{References}

CPW (2015a). http://preview.tinyurl.com/q9w9xlx. The CPW biography of Ingo Bauer. CPW (2015b). http://preview.tinyurl.com/ph94pc5. The CPW biography of the late Don Dailey. CPW (2015c). http://preview.tinyurl.com/oq5bp6x. The CPW biography of Erdogan Günes. CPW (2015d). http://preview.tinyurl.com/o934x5k. The CPW biography of Timo Haupt. CPW (2015e). http://preview.tinyurl.com/pc24n5q. The CPW biography of Raimund Heid. CPW (2015f). http://preview.tinyurl.com/pd3wglj. The CPW biography of Larry Kaufman GM. CPW (2015g). http://preview.tinyurl.com/p7qmuor. The CPW biography of Mark Lefler. CPW (2015h). http://preview.tinyurl.com/ozlu5m9. The CPW biography of Steve Maughan. CPW (2015i). http://preview.tinyurl.com/qej8djl. The CPW biography of Stefan Meyer-Kahlen. CPW (2015j). http://preview.tinyurl.com/pez8kko. The CPW biography of Richard Pijl. CPW (2015k). http://preview.tinyurl.com/o2stxnn. The CPW biography of Tessa Pijl. CPW (20151). http://preview.tinyurl.com/q6hmhmj. The CPW biography of Frank Schneider. CPW (2015m). http://preview.tinyurl.com/p3vpyby. The CPW biography of Christian Sommerfeld. CPW (2015n). http://preview.tinyurl.com/nr74dyd. The CPW biography of Mark Uniacke. CPW (2015o). http://preview.tinyurl.com/ozjkt73. The CPW biography of Harvey Williamson. CPW (2015p). http://preview.tinyurl.com/1xh7mh4. The CPW biography of Johannes Zwanzger. CPW (2015q). http://preview.tinyurl.com/nke2wcq. The CPW biography of FRIDOLIN. CPW (2015r). http://preview.tinyurl.com/pwg5jdj. The CPW biography of GINKGO. CPW (2015s). http://chessprogramming.wikispaces.com/Hiarcs. The CPW biography of HIARCS. CPW (2015t). http://chessprogramming.wikispaces.com/Jonny. The CPW biography of JONNY. CPW (2015u). http://preview.tinyurl.com/nm5ps9h. The CPW biography of KOMODO. CPW (2015v). http://preview.tinyurl.com/pvkhv5w. The CPW biography of MAVERICK. CPW (2015w). http://preview.tinyurl.com/ol88plm. The CPW biography of PROTECTOR. CPW (2015x). http://chessprogramming.wikispaces.com/Shredder. The CPW biography of SHREDDER. CPW (2015y). http://preview.tinyurl.com/ppnqeuz. The CPW biography of THE BARON. de Man, R. (2013). http://tablebase.sesse.net/syzygy/. Site providing 5- and 6-man DTZ ${ }_{50}{ }^{\prime}$ EGTs. ICGA (2015). WCCC 2015, pgn file. https://icga.leidenuniv.nl/?page_id=1260.

Krabbenbos, J., van den Herik, H.J. and Haworth, G.M C C. (2015). WCCC 2015: the $21^{\text {st }}$ World Computer Chess Championship. Added pgn file with some analysis at http://centaur.reading.ac.uk/39948/.

Müller, K. (2015). http://en.chessbase.com/post/the-trojan-horse-2 on the JONNY-KOMODO endgame. MVL (2015). http://tb7.chessok.com/probe/250/3232. Lomonosov server of s8m DTM data.

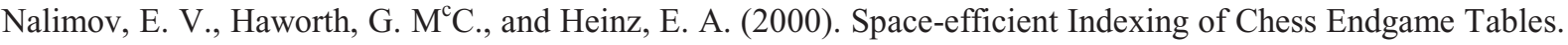
ICGA Journal, Vol. 23, No. 3, pp. 148-162.

Romero, P. P. (2012). FINALGEN: download, tutorial and examples. http:/www.mtu-media.com/finalgen.

Vlasák, E. (2015). HT - to use or not to use? EG, Vol. 21, No. 200, pp. 92-94. 